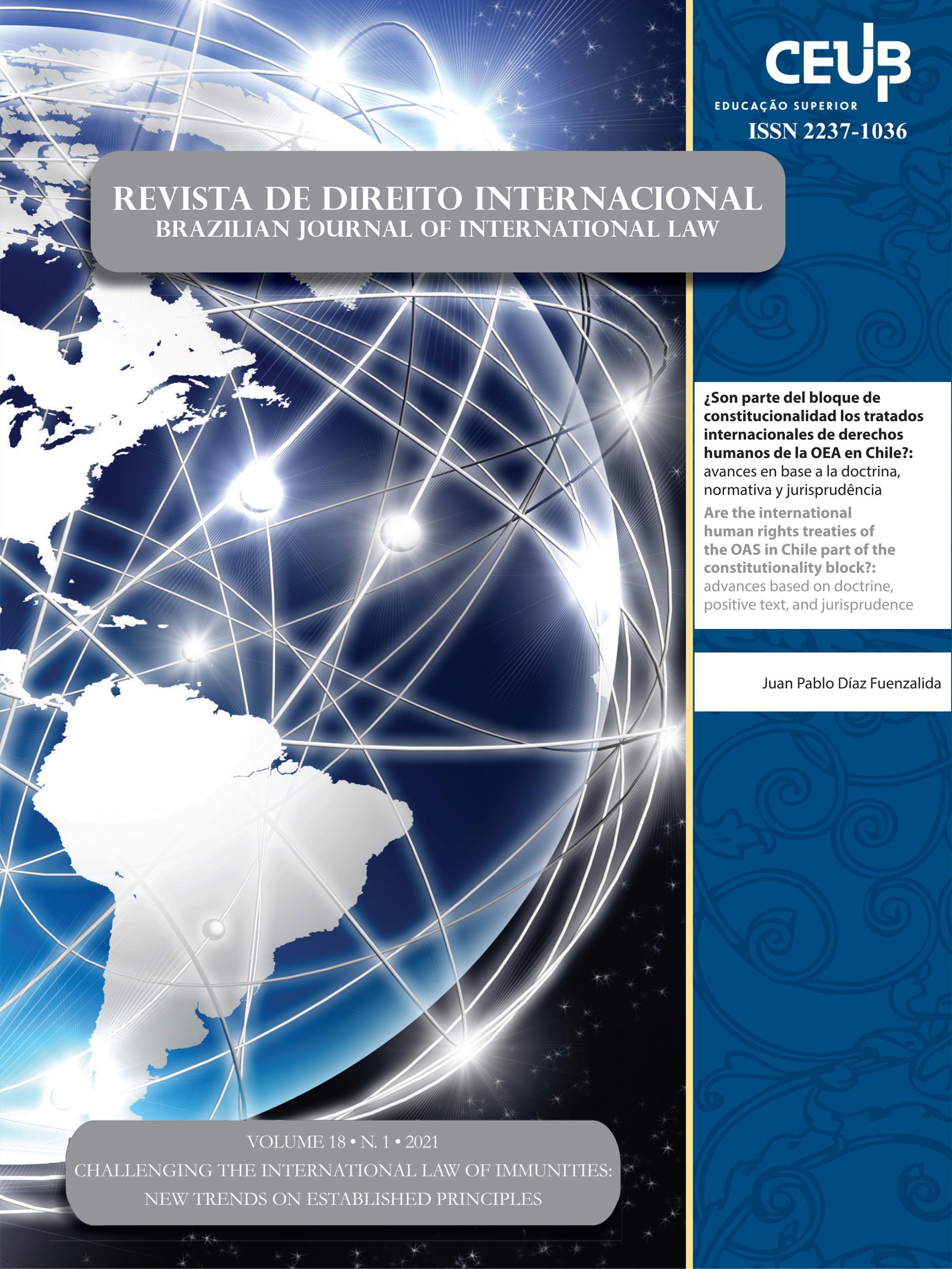


EDITORIAL

Challenging the International Law of Immunities: New Trends on Established Principles? An introduction to the special issue ............................................ 14

Lucas Carlos Lima, Loris Marotti e Paolo Palchetti

CrôniCAS........................................................................................ 17

RESPONSABILIDADE E IMUNIDADE DAS ORgANIZAÇÕES INTERNACIONAIS: PRÁTICA E DESAFIOS ...19 Vinícius Fox Drummond Cançado Trindade

The JURISDiCTIONAL IMMUNITY OF INTERNATIONAL ORgaNiZATIONS BEFORE THE BRAZILIAN SuPREMe Federal Court.

Bárbara Tuyama Sollero

The Law of State Immunity before the Brazilian Supreme Court: what is at stake WITH THE "ChANGRI-LA" CASE?

Aziz Tuffi Saliba e Lucas Carlos Lima

\section{Dossiê: Challenging the International Law of Immunities: New Trends} on Established Principles?

State Immunity and the Rights of Employees: Lights and Shadows of the Strasbourg COURT's JURISPRUdENCE .61

Pierfrancesco Rossi

A human Rights-BASEd CHALlENGE: THE KEY TO UNLOCK THE UN'S IMMUNiTY PROBLEM?...79 Héloïse Guichardaz

IMMUNITIES OF STATE OFFICIALS AND THE "FUNDAMENTALLY DIFFERENT NATURE" OF INTERNATIONAL COURTS: THE APPEALS CHAMBER DECISION IN THE JORDAN REFERRAL RE AL BASHIR ...97 Rita Guerreiro Teixeira e Hannes Verheyden 
IMUNIDADE DE JURISDIÇÃo dOS EsTADOS: O CAMINHO PARA A RELATIVIZAÇÃo

Vinícius Assis da Silveira, Luiz Felipe Costa Santana e Valesca Raizer Borges Moschen

The IMmUNity OF INTERNATIONAL ORganizations IN LABOUR DispUTES. DeVElopments BEFORE INTERNATIONAL TRIBUNALS, NATIONAL COURTS AND THE COLOMBIAN JURISDICTION ..... 137 Walter Arévalo-Ramirez e Ricardo Abello-Galvis

Imunidade de Jurisdição dos Estados E Poder Executivo brasileiro: os Pareceres dos CONSULTORES JURÍDICOS DO ITAMARATY

George Rodrigo Bandeira Galindo

Artigos SOBRe outros temas

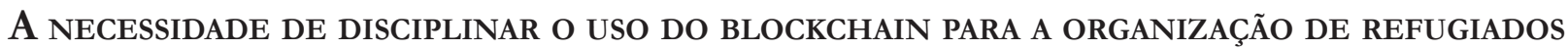
PELO DIREITO INTERNACIONAL. 195

Agatha Gonçalves Santana, Carla Noura Teixeira e Otavio Noura Teixeira

O TRABALHO INFANTIL DE MIGRANTES E REFUgIADOS VENEZUELANOS NO BRASIL

André Viana Custódio e ohana Cabral

THE NEW BRAZILIAN ANTI-TRAFFICKING LAW: CHALLENGES AND OPPORTUNITIES TO COVER THE NORMATIVE LACK . 243 Waldimeiry Correa da Silva

¿SON PARTE DEL BLOQUE DE CONSTITUCIONALIDAD LOS TRATADOS INTERNACIONALES DE DERECHOS HuMANOS DE LA OEA EN CHILE?: AVANCES EN BASE A LA DOCTRINA, NORMATIVA Y JURISPRUDÊNCIA. 270

Juan Pablo Díaz Fuenzalida

O Tratado de Saint-Germain-En-Laye e os Efeitos do instituto da “opÇão” Sobre a CONDIÇÃO JURÍDICA DOS DESCENDENTES DE CIDADÃOS AUSTRÍACOS TRENTINO-TIROLÊSES ......290 Arno Dal Ri Jr. e Andrey José Taffner Fraga

Control Judicial de la Corte Interamericana de Derechos Humanos y Programas Masivos de Reparaciones: Hacia un Enfoque más Matizado .309 Juan Carlos Ochoa-Sánchez 
JuSTICIABILIDADE DIRETA DOS DIREITOS ECONÔMICOS, SOCIAIS, CULTURAIS E AMBIENTAIS NA

Corte Interamericana DE Direitos Humanos..........................................................334

Augusto Antônio Fontanive Leal e Guilherme Massaú

How the indigenous case of Xukuru before the Inter-American Court of Human RiGHTS CAN INSPIRE DECOLONIAL COMPARATIVE STUDIES ON PROPERTY RIGHTS..........................353

Flavianne Fernanda Bitencourt Nóbrega e Camilla Montanha 


\title{
¿Son parte del bloque de constitucionalidad los tratados internacionales de derechos humanos de la OEA en Chile?: avances en base a la doctrina, normativa y jurisprudência*
}

\author{
Are the international human rights \\ treaties of the OAS in Chile part of the \\ constitutionality block?: advances based on \\ doctrine, positive text, and jurisprudence
}

Juan Pablo Díaz Fuenzalida**

\section{Resumen}

El presente trabajo estudia si los principales tratados internacionales de derechos humanos de la Organización de Estados Americanos (OEA) son parte del bloque de constitucionalidad en Chile. Para responder a aquella interrogante se sintetizan los principales argumentos doctrinarios para aplicar los tratados sobre derechos humanos en Chile; se analiza la normativa constitucional chilena para considerar los tratados referidos; y, finalmente se comprueba si los tratados citados son utilizados en los máximos tribunales de justicia. Se desarrolla cada punto anterior con doctrina, normativa nacional e internacional y con jurisprudencia. La investigación cristaliza al evidenciar que desde todos los prismas son aplicables cada uno de los tratados revisados en Chile. Las conclusiones son que los principales tratados sobre derechos de la OEA son parte del bloque de constitucionalidad en Chile, tanto en el texto positivo como en la práctica en los tribunales de justicia, abriendo un abanico de derechos fundamentales para todos los habitantes. Sin embargo, también se hace el llamado de atención en que hay algunos que todavía hace falta incorporar y sobre aquellos que han sido ratificados, pero con algunas declaraciones o reservas que están íntimamente relacionados con derechos humanos elementales.

Palabras clave: Bloque de constitucionalidade. Tratados Internacionales sobre Derechos Humanos. Organización de los Estados Americanos (OEA).

** Doctor en Derecho, Máster en Gobernanza y Derechos Humanos, ambos por la Universidad Autónoma de Madrid; Magister en Docencia Universitaria, Licenciado en Ciencias Jurídicas y Sociales, ambos por la Universidad Autónoma de Chile; profesor de Derecho Constitucional e investigador adscrito al Instituto de Investigación en Derecho de la Universidad Autónoma de Chile; Editor alterno de la Revista Justicia y Derecho de la Universidad Autónoma de Chile. Dirección postal: Avenida Pedro de Valdivia 425, Providencia, Santiago de Chile Email: juanpablo.diaz@uautonoma.cl

\section{Abstract}

This paper studies whether the main international human rights treaties of the Organization of American States (OAS) are part of the constitutionality block in Chile. To answer that question, the main doctrinal arguments for applying human rights treaties in Chile are synthesized; Chilean constitutional regulations are analyzed to consider the treaties; and, finally, it is checked whether the treaties are used in the highest courts of justice. Each 
point above is developed with doctrine, national and international regulations, and jurisprudence. The research crystallizes by showing that each of the revised treaties in Chile are applicable from all perspectives. The conclusions are that the main treaties on rights of the OAS are part of the constitutionality block in Chile, both in the positive text and in practice in the courts of justice, opening a range of fundamental rights for all inhabitants. However, there is also a call for attention that there are some that still need to be incorporated and those that have been ratified, but with some declarations or reservations that are intimately related to elementary human rights.

Keywords: Constitutionality block. International Treaties of Human Rights. Organization of American States (OAS).

\section{Introducción: el objeto de la investigación}

Aplicar la Constitución en Chile es más que el mero texto normativo aprobado en el 1980 o bien, por el constituyente derivado del 2005 con todas las modificaciones hasta la fecha. Hoy en día se habla de "bloque de constitucionalidad" que contendría una serie de normas relacionadas a la Carta Fundamental. Así, por ejemplo, para el caso colombiano, y, en general, se sigue así en los demás países, se ha dicho que el bloque de constitucionalidad está conformado: "no sólo por el articulado de la Constitución, sino que, entre otros, por los tratados internacionales que trata el artículo 93 de la Carta Fundamental, por las leyes orgánicas y, en algunas ocasiones, por las leyes estatutarias". ${ }^{1}$ Ello tiene vital importancia en la promoción y protección de los derechos humanos en los tribunales de justicia, evidenciándose incluso en los resultados de acciones y recursos en favor de las personas, ya sea citando expresamente los tratados o considerando sus criterios. ${ }^{2}$ Además es positivo para el transjudicialismo, ${ }^{3}$ en el sentido que no

\footnotetext{
1 MORALES, Alejandra Virginia Morales; ODIMBA ON'ETAMBALAKO WETSHOKONDA, Jean Cadet. La incorporación del concepto del bloque de constitucionalidad en matéria de derechos humanos en México. Prolegómenos: Derechos y Valores, Bogotá, v. 12, n. 27, p. 135-14, ene./jun. 2011.

2 DÍAZ TOLOSA, Regina Ingrid. Expulsion of aliens: the application of International Law by Chilean Superior Courts. Revista de Direito Internacional, Brasilia, v. 17, n. 2, p. 308-330, 2020.

3 PEREIRA, Ruitemberg Nunes. Interações transjudiciais e transju-
}

se sobrecargarán los máximos tribunales, especialmente internacionales con casos que pueden ser resueltos en pro de los derechos humanos a nivel nacional.

Esta temática, que ya es compleja de ser revisada por las interacciones y diálogos entre derecho nacional e internacional y sus actores, ${ }^{4}$ (o como se verá en el transcurso del presente trabajo, que para el caso chileno se conforma un único sistema que, inclusive, da prevalencia al derecho internacional de los derechos humanos por sobre su soberanía, o bien, en virtud de su soberanía se autolimita al respecto), se suma que cada vez es más difícil tener un manejo de la normativa que debe aplicarse. Dicho fenómeno es un acontecer que Natalino Irti estudió hace cerca de treinta años, pero lamentablemente se ha acrecentado aún más su diagnóstico. Irti en los años 80-90 explicaba como las instituciones de derecho civil italiano se iban expandiendo a otros cuerpos normativos, distintos del Código Civil, siendo la especialidad un factor a considerar para cada caso concreto. ${ }^{5}$ Ocurre exactamente lo mismo al dilucidar cuál es el bloque de constitucionalidad, la normativa que hay que considerar no sólo es de ley orgánica que desarrolle a las Cartas Fundamentales, sino que hoy hay que revisar si son o no aplicables una serie de tratados internacionales relacionados con el Derecho Constitucional.

En efecto, entre otras normas relevantes que podrían ser parte del bloque de constitucionalidad en un país, especialmente considerando al caso de Chile, son los tratados sobre derechos humanos creados a propósito de la Organización de Estados Americanos (OEA). Todo esto comienza con la Declaración Americana de los Derechos y Deberes del Hombre de la IX Conferencia Internacional Americana. ${ }^{6}$ Es similar a lo ocurrido en el contexto de Naciones Unidas (ONU) con la Declaración Universal de Derechos Humanos. ${ }^{7}$ Sólo ocho países se abstuvieron de votar y ninguna nación votó

dicialismo: sobre a linguagem irônica no direito internacional. Revista de Direito Internacional, Brasilia, v. 17, n. 2, p. 169-199, 2020. 4 VARELLA, Marcelo. D. Internacionalização do Direito: superação do paradigma estatal e a insuficiência de estruturas de diálogos. Revista de Direito Internacional, v. 9, n. 4, p. 1-5, 2012.

${ }^{5}$ IRTI, Natalino. La edad de la descodificación. España: J. M. Bosch Editor, 1992.

${ }^{6}$ ORGANIZACIÓN DE LOS ESTADOS AMERICANOS. Declaración Americana de los Derechos y Deberes del Hombre, de 1948. Disponible en: http://www.oas.org/es/cidh/mandato/Basicos/declaracion.asp Acceso en: 26 oct. 2020.

7 NACIONES UNIDAS. Declaración Universal de Derechos Humanos, de 1948. Disponible en: https://www.un.org/es/universal-declaration-human-rights/ Acceso en: 26 oct. 2020. 
en contra. Así, por primera vez las naciones del mundo se ponían de acuerdo en un texto que reconociera los Derechos Fundamentales de las personas. ${ }^{8}$ No siendo obligatoria la resolución, es una verdadera hoja de ruta que marca el camino a seguir en materia de Derechos Humanos. ${ }^{9}$ Y, en el contexto regional, como decíamos entramos a la Declaración citada, conocida como Carta Magna del sistema interamericano. Fue concebida como un instrumento no vinculante. Surgió como un manifiesto político, nos recuerda Paúl Díaz. ${ }^{10} \mathrm{Y}$, ha tenido una especial repercusión en tal sentido por los tratados sobre derechos humanos que posteriormente se han creado en el contexto de la OEA.

De manera que es de suma importancia establecer si para un país son o no parte de su bloque de constitucionalidad, pues ello abre un abanico de derechos fundamentales para sus habitantes, que, sólo en cuantía (si lo evaluamos desde el número de páginas) a lo menos duplica el catálogo de derechos esenciales para los ciudadanos o bien profundiza en cada uno de ellos. Y, además para el caso particular de Chille son aún más relevantes por el actual proceso constituyente que está pasando. En efecto, el 25 de octubre se preguntó a la ciudadanía sí aprueba o rechaza redactar un nuevo texto constitucional, ganando la opción apruebo. Podría pensarse que es una especie de hoja en blanco. Sin embargo, el acuerdo político y normativa que regula el proceso, concretamente en el artículo 135 de la Constitución Política chilena, ${ }^{11}$ considera a los tratados internacionales como límite en la redacción del nuevo texto constitucio-

\footnotetext{
${ }^{8}$ MARTÍN-RETORTILLO BAQUER, Lorenzo. Una visión de la tutela judicial a partir de la jurisprudencia de la Corte Interamericana y del Tribunal Europeo de Derechos Humanos. In: FERRER MAC GREGOR, Eduardo; HERRERA GARCÍA, Alfonso (coord.). Diálogo jurisprudencial en derechos bumanos: entre Tribunales Constitucionales y Cortes Internacionales: in memoriam Jorge Carpizo, generador incansable de diálogos. México: Tirant lo Blanch, 2013. p. $1217-1260$.

9 NACIONES UNIDAS. Historia de la redacción de la Declaración Universal de Derechos Humanos. Disponible en: http://www.un.org/es/ documents/udhr/history.shtml Acceso en: 26 oct. 2020.

10 PAÚL DÍAZ, Álvaro. La Génesis de la Declaración Americana de los Derechos y Deberes del Hombre y la Relevancia Actual de sus Trabajos Preparatorios. Revista de Derecho de la Pontificia Universidad Católica de Valparaíso, Valparaíso, n. 47, p. 361-395, 2016.

IRTI, Natalino. La edad de la descodificación. España: J. M. Bosch Editor, 1992.

11 CHILE. Decreto 100. Fija el texto refundido, coordinado y sistematizado de la Constitucion Politica de la Republica de Chile. Disponible en: https://www.bcn.cl/leychile/navegar?idNorma $=242302$ Acceso en: 26 oct. 2020.
}

nal, concretamente, que deben respetarse. ${ }^{12}$ La norma es amplia dado que consagra a tratados internacionales de toda especie. En este punto, es preciso delimitar que para efectos de esta investigación se estudiarán aquellos relacionados con derechos humanos y no otros que puedan ser parte de la OEA pero que estén llamados a regular otras materias.

Con todo, la presente investigación se plantea como objetivo general determinar si son parte o no del bloque de constitucionalidad los tratados internacionales sobre derechos humanos de la OEA en el Estado de Chile. Para ello, es menester determinar objetivos específicos que tributen al objetivo general. Estos objetivos particulares son:

1. Sintetizar los principales argumentos doctrinarios para aplicar los tratados sobre derechos humanos en Chile.

2. Revisar la normativa aplicable sobre cada tratado concreto de la OEA para aplicarlos en Chile.

3. Comprobar que los tratados revisados sean aplicados en los máximos tribunales de justicia en Chile.

Así, metodológicamente se evidenciará con doctrina, normativa y jurisprudencia relacionada a cada uno de los objetivos específicos. Se utilizará metodología que se ha considerado en otros artículos como se ha hecho con normativa de la $\mathrm{ONU},{ }^{13}$ pero es preciso estudiar aquellos tratados de derechos humanos de la OEA, lo que es un valor agregado al respecto y factor diferenciador con otros trabajos. Con el desarrollo de cada uno de los objetivos se podrá responder claramente si los tratados internacionales sobre derechos humanos de la OEA son o no parte del bloque de constitucionalidad en Chile. Y, de esta manera dilucidar puntos a favor y aspectos que mejorar hacia el futuro siendo siempre propositivo en la promoción y protección de los derechos humanos.

\footnotetext{
12 En el inciso pertinente, el artículo 135 consagra: "El texto de Nueva Constitución que se someta a plebiscito deberá respetar el carácter de República del Estado de Chile, su régimen democrático, las sentencias judiciales firmes y ejecutoriadas y los tratados internacionales ratificados por Chile y que se encuentren vigentes".

${ }^{13}$ DÍAZ FUENZALIDA, Juan Pablo. ¿Son parte del bloque de constitucionalidad los principales tratados internacionales de derechos humanos de la ONU en Chile? Del texto positivo a la aplicación en tribunales de justicia. Revista Brasileira de Políticas Públicas, v. 9, n. 1, p. 153-172, 2019.
} 


\section{Argumentos doctrinarios y normativos para incluir a los tratados sobre derechos humanos de la OEA en el bloque de constitucionalidad chileno.}

En el año 1989 se realiza una reforma constitucional en Chile que modifica el inciso segundo del artículo 5 de la Carta Fundamental. En efecto, en su antigua redacción, se consagraba que el ejercicio de la soberanía reconoce como limitación el respeto a los derechos esenciales que emanan de la naturaleza humana. Ello traía complejidades en la interpretación ¿Cuáles eran aquellos derechos? Y es así como, en virtud de la Ley de Reforma Constitucional $\mathrm{N}^{\circ}$ 18.825, de 17 de agosto de 1989, ${ }^{14}$ que se agregó una parte, dando mayor certeza, encuadrando los derechos esenciales de la naturaleza humana en aquellos garantizados por la Constitución, así como por los tratados internacionales ratificados por Chile y que se encuentren vigentes. Hoy, dicha redacción sigue intacta.

La redacción de la reforma del año 1989 de la Constitución chilena, tan explicita haciendo referencia a los tratados internacionales no era sólo por certeza jurídica, sino que era necesaria para la aplicación de los tratados en tribunales de justicia. En tal sentido, nos recuerda el profesor Francisco Cumplido Cereceda que, de forma esporádica los Juzgados y Cortes aplicaban directamente las normas de la Constitución y, respecto de los tratados exigían frecuentemente una legislación que recepcionara lo convenido. ${ }^{15}$ Es decir, una ley que los pusiera en práctica o desarrollo a pesar de ya haber sido ratificados por el país. Y, adiciona el profesor que durante el periodo de 1973 a 1989, como no se había publicado ciertos tratados en el Diario Oficial, los tribunales se excusaban de que no estaban aún vigentes para Chile. ${ }^{16}$ Un ejemplo de esto último son el Pacto de Derechos

\footnotetext{
14 CHILE. Ley de reforma constitucional $N^{\circ} 18.825$, de 17 de agosto de 1989. Disponible en: http://www.leychile.cl/Navegar/scripts/obtie nearchivo?id=recursoslegales $/ 10221.3 / 44169 / 2 /$ HLArt5CPR.pdf Acceso en: 26 oct. 2020.

15 CUMPLIDO CERECEDA, Francisco. La reforma constitucional de 1989 al inciso $2^{\circ}$ del artículo $5^{\circ}$ de la Constitución: sentido y alcance de la reforma. Doctrina y Jurisprudencia. Ius et Praxis, Talca, v. 9, n 1, p. 365-374, 2003.

16 CUMPLIDO CERECEDA, Francisco. La reforma constitucional de 1989 al inciso $2^{\circ}$ del artículo $5^{\circ}$ de la Constitución: sentido y alcance de la reforma. Doctrina y Jurisprudencia. Ius et Praxis, Talca, v. 9, n 1, p. 365-374, 2003.
}

Civiles y Políticos promulgado en 1976, y publicado trece años después, sólo en abril de 1989, o, como con el Pacto Internacional de Derechos Económicos y Sociales, ratificado en 1976 y promulgado y publicado el 27 de mayo de 1989.

Ahora bien, desde dicha reforma, tendremos de todas maneras que incluir en el bloque de constitucionalidad a ciertos tratados internacionales sobre derechos humanos. Ello, como muy bien explicaba el profesor Humberto Nogueira Alcalá, con la modificación que se hizo al texto constitucional del artículo 5 en el año $1989,{ }^{17}$ que reza lo que sigue:

El ejercicio de la soberanía reconoce como
limitación el respeto a los derechos esenciales que
emanan de la naturaleza humana. Es deber de
los órganos del Estado respetar y promover tales
derechos, garantizados por esta Constitución, así
como por los tratados internacionales ratificados
por Chile y que se encuentren vigentes.

De ello podemos afirmar que el límite de la soberanía son los derechos esenciales que emanan de la naturaleza humana, es decir, de los derechos humanos. Según Nogueira Alcalá, estos derechos serían:

a) los que la Carta Fundamental explicita sin taxatividad en el artículo $19^{\circ} ;^{18}$

b) los que asegura el derecho internacional a través de los principios de ius cogens; los que asegura el derecho convencional internacional de derechos humanos y derecho humanitario y los que asegura el derecho internacional consuetudinario.

c) Los derechos esenciales implícitos que puedan desarrollarse en el futuro, respecto de los cuales no hay reconocimiento aún a través de las diversas fuentes del derecho interno o internacional. ${ }^{19}$

Además, no sólo son obligatorios los tratados sobre derechos humanos por las normas constituciona-

CHILE. Decreto 100. Fija el texto refundido, coordinado y sistematizado de la Constitucion Politica de la Republica de Chile. Disponible en: https://www.bcn.cl/leychile/navegar?idNorma $=242302$ Acceso en: 26 oct. 2020.

18 Para el lector no familiarizado con la Constitución chilena, vale informar que en el artículo 19 se encuentra una serie de garantías constitucionales, incluidas en 26 numerales, en que se desarrollan las libertades y derechos fundamentales tales como, la vida, la igualdad ante la ley, la privacidad, protección de datos personales, derecho a vivir en un medio ambiente libre de contaminación, derecho de propiedad, protección del trabajo, seguridad social, derecho a la salud, derecho a la educación, libertad de enseñanza, libertad de conciencia, entre otros.

19 NOGUEIRA ALCALÁ, Humberto. Los derechos esenciales o humanos contenidos en los tratados internacionales y su ubicación en el ordenamiento jurídico nacional: doctrina y jurisprudencia. Ius et Praxis, Talca, v. 9, n. 1, p. 403-466, 2003. 
les chilenas, también lo son por asuntos de observancia internacional. En efecto, Gozaíni al analizar la obligatoriedad de determinados tratados internacionales que afectan a los países latinoamericanos y europeos, nos recuerda a la Convención de Viena sobre Derechos de los Tratados ${ }^{20}$. En efecto, el artículo 26 consagra al respecto al "Pacta sunt servanda", todo tratado en vigor obliga a las partes y debe ser cumplido por ellas de buena fe. Es decir, lo pactado obliga, pero además debe ser cumplido, de forma efectiva para que lo suscrito y ratificado no sea una mera ilusión. Y, además, el artículo 27 que expresa que, "El derecho interno y la observancia de los tratados. Una parte no podrá invocar las disposiciones de su derecho interno como justificación del incumplimiento de un tratado. Esta norma se entenderá sin perjuicio de lo dispuesto en el artículo 46". ${ }^{21}$ Mayor fuerza aún, es decir, ni siquiera con derecho interno se puede obstaculizar la aplicación de un tratado internacional. Este último tratado, es decir, la Convención de Viena, ha entrado en vigor internacional en enero de $1980,{ }^{22} \mathrm{y}$ Chile lo ha ratificado en el año $1981 .{ }^{23}$ Por lo que desde ese punto de vista los tratados que haya ratificado le son aplicables.

A mayor abundamiento, Chile ha mostrado un real interés en estar al día en materia de derechos esenciales, lo que se ha cristalizado en la suscripción y ratificación de tratados sobre derechos humanos. Así, Díaz Tolosa nos recuerda que:

\footnotetext{
La tradición en Chile ha sido respetar las normas del Derecho internacional; además forma parte de los sistemas universal y regional de protección de los derechos humanos y uno de los pilares fundamentales de su sistema político democrático es la protección a la dignidad humana. ${ }^{24}$
}

${ }^{20}$ GOZAÍNI, Osvaldo. Derecho Procesal Transnacional: los procedimientos en la Comisión y ante la Corte Interamericana de Derechos Humanos. México: Tirant lo Blanch, 2014.

${ }^{21}$ NACIONES UNIDAS. Convención de Viena sobre el Derecho de los Tratados, Resolución A/CONF.39/27, de 23 de mayo de 1969. Disponible en: https://treaties.un.org/doc/Treaties/1980/01/19800127\%20 00-52\%20AM/Ch_XXIII_01.pdf Acceso en: 26 oct. 2020.

22 NACIONES UNIDAS. Status of Treaties: Chapter XXIII. Law of Treaties. 1. Vienna Convention on the Law of Treaties. Disponible en: https://treaties.un.org/doc/Publication/MTDSG/Volume $\% 20$ II/Chapter\%20XXIII/XXIII-1.en.pdf Acceso en: 26 oct. 2020.

23 CHILE. Decreto Supremo 381. Promulga la Convencion sobre el Derecho de los Tratados y su anexo, suscrita por el Gobierno de Chile em Viena, el 23 de mayo de 1969. Disponible en: https:// www.bcn.cl/leychile/navegar?idNorma=12889\&idParte $=0$ \&idVers ion= Acceso en: 26 oct. 2020.

${ }^{24}$ DÍAZ TOLOSA, Regina Ingrid. Aplicación judicial en Chile del "ius cogens" como manifestación de la internacionalización del
Así, ya es posible afirma que:

1. Los principales tratados sobre derechos humanos de la OEA son parte del bloque de constitucionalidad por contener normas de IUS COGENS.

2. En caso de no seguir doctrinas ius naturalistas o ser más formalistas exigiendo una norma o acuerdo internacional, los principales tratados sobre derechos humanos de la OEA son parte del bloque de constitucionalidad, siempre y cuando estén ratificados por Chile y estos se encuentren vigentes, aplicando el Tratado de Viena (en concreto el pacta sunt servanda y el principio de buena fe de los tratados).

3. En caso de no seguir doctrinas ius naturalista, y si se le quiere dar mayor fuerza obligatoria a la soberanía nacional (normas constitucionales) que, a los acuerdos entre partes internacionales, los principales tratados sobre derechos humanos de la OEA son parte del bloque de constitucionalidad, siempre y cuando estén ratificados por Chile y estos se encuentren vigentes, aplicando el artículo 5 inciso segundo de la Constitución chilena.

Ello deviene incluso, como se decía, del Derecho Internacional, que debe tener una especial preocupación por los tratados de derechos humanos, incluso, haciendo necesario que el poder judiciario garantice la aplicación de estos instrumentos. Es más, se ha dicho que los derechos humanos reconocidos en las Convenciones y tratados, entre otros, tienen por objeto ampliar la gama de derechos fundamentales y no a reemplazarlos. ${ }^{25} \mathrm{O}$, incluso desde libertades económicas se pueden incluir una serie de derechos fundamentales que están incluidos en los tratados internacionales. Así, para el caso chileno, se garantiza constitucionalmente poder realizar actividades económicas, lo que viene acompañado por libertades y derechos como el de asociación, personalidad jurídica, entre otras. ${ }^{26}$

Derecho interno en materia de protección de la dignidad humana. Revista de Derecho de la Pontificia Universidad Católica de Valparaíso, Valparaíso, n. 40, p. 393-417, 2013.

${ }^{25}$ TOMÉ DA MATA, Edilney; GOMEZ CORREIO, Eduardo Bianchi. Responsabilidad Internacional del Estado frente a lucha contra la discriminación racial y étnica en España. Revista de Direito Internacional, Brasilia, v. 13, n. 1, p. 347-363, 2016.

${ }^{26}$ DÍAZ FUENZALIDA, Juan Pablo; VILLAMIL RODRÍGUEZ, 
Más aún, es menester agregar que los tratados han indo más allá del bloque de constitucionalidad, o, podría afirmarse que forjan su estructura. Así, el artículo 135, inciso final de la Constitución Política de Chile, ${ }^{27}$ se refiere a los límites que debiera considerar la Convención que podría redactar una Nueva Constitución:

\begin{abstract}
Artículo 135. Disposiciones especiales.
El texto de Nueva Constitución que se someta a plebiscito deberá respetar el carácter de República del Estado de Chile, su régimen democrático, las sentencias judiciales firmes y ejecutoriadas y los tratados internacionales ratificados por Chile y que se encuentren vigentes.
\end{abstract}

Como se constata, la Convención tiene una especie de hoja en blanco, pero que en realidad es un croquis con un entramado se base o sustento, en que se incluye a los tratados internacionales. Ello encuadra perfectamente con el artículo 5, inciso segundo de la Constitución, es decir, con los límites de la soberanía. De manera que ni la redacción ni la ratificación de los ciudadanos respecto de una Nueva Constitución debiera ir en contra de los tratados internacionales, especialmente si tratan sobre derechos humanos.

\section{Revisión de normativa aplicable por tratado internacional de derechos humanos de la OEA en Chile: ¿Cuáles cumplen con todos los requisitos doctrinarios-normativos?}

Del punto anterior, podemos sintetizar que, serían parte del bloque de constitucionalidad aquellos tratados internacionales de la OEA que Chile ha suscrito, ratificado, y, que estos se encuentren en vigor, referido en esencia a su vigencia internacional. En adelante, se pasa a revisar la normativa que otorga estos requisitos de una serie de tratados internacionales de derechos humanos de la OEA, que, valga la redundancia, desde lo normativo, son parte del bloque de constitucionalidad chileno.

Juan Sebastián. La otra cara de la moneda: protección constitucional de la empresa, el emprendimiento y la libre competencia en Chile y Colombia. Revista de Direito Internacional, Brasilia, Brasil, v. 17, n. 1, p. 230-256, 2020.

27 CHILE. Decreto 100. Fija el texto refundido, coordinado y sistematizado de la Constitucion Politica de la Republica de Chile. Disponible en: https://www.bcn.cl/leychile/navegar?idNorma $=242302$ Acceso en: 26 oct. 2020.
En primer lugar, encontramos a la Convención interamericana sobre concesión de los derechos políticos a la mujer. Adoptada en Bogotá, se creó por la Resolución A-44 de la OEA, de 2 de mayo de $1948 .{ }^{28}$ Y, Chile ha ratificado el tratado, en 1975, según consta en el Decreto Supremo 309, de 26 de mayo de $1975 .{ }^{29}$

En segundo lugar, encontramos a la Convención interamericana sobre la concesión de derechos civiles a la mujer. Adoptada en Bogotá, se creó por la Resolución A-45 de la OEA, de 2 de mayo de $1948 .^{30}$ Y, Chile ha ratificado el tratado, en 1975, según consta en el Decreto Supremo 310, de 26 de mayo de $1975 .^{31}$

En tercer lugar, encontramos a la Convención americana sobre derechos humanos. Adoptada en San José de Costa Rica, el 22 de noviembre de 1969, se creó por la Resolución B-32 de la OEA y con vigencia internacional desde el 18 de julio de $1978 .{ }^{32}$ Y, Chile ha ratificado el tratado, en 1990, según consta en el Decreto Supremo 873, de 5 de enero de 1991, ${ }^{33}$ aunque con la siguiente declaración:

a) El Gobierno de Chile declara que reconoce la competencia de la Comisión Interamericana de Derechos Humanos, por tiempo indefinido y bajo condiciones de reciprocidad, para recibir y examinar las comunicaciones en que un Estado Parte alegue que otro Estado Parte ha incurrido en violaciones de derechos humanos establecidos en la Convención Americana sobre Derechos Humanos, en los términos previstos en el artículo 45 de la mencionada Convención. 26 oct. 2020 . 
b) El gobierno de Chile declara que reconoce como obligatoria de pleno derecho la competencia de la Corte Interamericana de Derechos Humanos respecto de los casos relativos a la interpretación y aplicación de esta Convención de conformidad con lo que dispone su artículo 62.

$\mathrm{Al}$ formular las mencionadas Declaraciones, el Gobierno de Chile deja constancia que los reconocimientos de competencia que ha conferido se refieren a hechos posteriores a la fecha del depósito de este Instrumento de Ratificación o, en todo caso, a hechos cuyo principio de ejecución sea posterior al 11 de marzo de 1990. Igualmente el Gobierno de Chile, al conferir la competencia a la Comisión y a la Corte Interamericana de Derechos Humanos, declara que estos órganos, al aplicar lo preceptuado en el párrafo segundo del artículo 21 de la Convención, no podrán pronunciarse acerca de las razones de utilidad pública o de interés social que se hayan tenido en consideración al privar de sus bienes a una persona.

En cuarto lugar, encontramos a la Convención interamericana para prevenir y sancionar la tortura. Adoptada en Cartagena de Indias, el 9 de diciembre de 1985, se creó por la Resolución A-51 de la OEA y con vigencia internacional desde el 28 de febrero de $1987 .{ }^{34}$ Y, Chile ha ratificado el tratado, en 1988, según consta en el Decreto Supremo 809, de 26 de noviembre de 1988, ${ }^{35}$ aunque con algunas reservas, como sigue:

a) $\mathrm{Al}$ artículo $4^{\circ}$, en cuanto modifica el principio de la "obediencia reflexiva" consagrado en la legislación interna chilena, en el sentido de que el Gobierno de Chile aplicará lo dispuesto en dicha norma internacional al personal sujeto al Código de Justicia Militar, respecto a los subalternos, siempre que la orden, notoriamente tendiente a la perpetración de los actos indicados en el artículo $2^{\circ}$, no sea insistida por el superior ante la representación del subalterno.

b) Al inciso final del artículo 13, en razón del carácter discresional y subjetivo en que está redactada la norma.

c) El Gobierno de Chile declara que en sus relaciones con los Países Americanos que sean Partes en la presente Convención, aplicará esta Convención en los casos en que existan incompatibilidades entre sus dis-

\footnotetext{
${ }^{34}$ ORGANIZACIÓN DE LOS ESTADOS AMERICANOS. Convención interamericana para prevenir y sancionar la tortura. Resolución A-51, de 9 de diciembre de 1985. Disponible en: http:/ / www.oas. org/juridico/spanish/tratados/a-51.html Acceso en: 26 oct. 2020.

${ }_{35}$ CHILE. Decreto Supremo 809, de 26 de noviembre de 1988. Disponible en: https://www.bcn.cl/leychile/navegar?idNorma=15728\&idP arte $=0$ \&idVersion $=$ Acceso en: 26 oct. 2020 .
}

posiciones y las de la Convención contra la Tortura y otros Tratos o Penas Crueles, Inhumanos o Degradantes, adoptada por las Naciones Unidas en 1984.

d) $\mathrm{Al}$ inciso tercero del artículo $8^{\circ}$, en cuanto un caso sólo podrá ser sometido a instancias internacionales cuya competencia haya sido aceptada expresamente por el Estado de Chile.

En quinto lugar, encontramos al Protocolo a la Convención Americana sobre derechos humanos relativos a la abolición de la pena de muerte. Adoptada en Asunción, el 8 de junio de 1990, se creó por la Resolución A-53 de la OEA y con vigencia internacional desde para los Estados que lo ratifiquen o se adhieran a él, a partir del depósito del correspondiente instrumento de ratificación o adhesión en la Secretaría General de la Organización de los Estados Americanos. ${ }^{36} \mathrm{Y}$, Chile ha ratificado el tratado, en 2008, según consta en el Decreto Supremo 252, de 16 de diciembre de 2008, ${ }^{37}$ aunque con la siguiente reserva:

El Estado de Chile formula la reserva autorizada por el Artículo 2, párrafo 1, del Protocolo a la Convención Americana sobre Derechos Humanos Relativo a la Abolición de la Pena de Muerte y, en consecuencia, podrá aplicar la pena de muerte en tiempo de guerra conforme al Derecho Internacional por delitos sumamente graves de carácter militar.

En sexto lugar, encontramos a la Convención interamericana sobre desaparición forzada de personas. Adoptada en Belem do Pará, el 9 de junio de 1994, se creó por la Resolución A-60 de la OEA y con vigencia internacional desde el 28 de marzo de $1996 .{ }^{38}$ Y, Chile ha ratificado el tratado, en 2010, según consta en el Decreto Supremo 12, de 24 de febrero de 2010. ${ }^{39}$

En séptimo lugar, encontramos a la Convención interamericana para prevenir, sancionar y erradicar la

${ }_{36}$ ORGANIZACIÓN DE LOS ESTADOS AMERICANOS. Protocolo a la Convención Americana sobre derechos humanos relativos a la abolición de la pena de muerte. Resolución A-53, de 8 de junio de 1990. Disponible en: http://www.oas.org/juridico/spanish/ tratados/a-53.html Acceso en: 26 oct. 2020.

37 CHILE. Decreto Supremo 252, de 16 de diciembre de 2008. Disponible en: https://www.bcn.cl/leychile/navegar?idNorma=283525 Acceso en: 26 oct. 2020.

38 ORGANIZACIÓN DE LOS ESTADOS AMERICANOS. Convención interamericana sobre desaparición forzada de personas. Resolución A-60, de 9 de junio de 1994. Disponible en: http:/ /www.oas. org/juridico/spanish/tratados/a-60.html Acceso en: 26 oct. 2020.

39 CHILE. Decreto Supremo 12, de 24 de febrero de 2010. Disponible en: https://www.leychile.cl/Navegar?idNorma=1011251 Acceso en: 26 oct. 2020. 
violencia en contra de la mujer. Adoptada en Belem do Pará, el 9 de junio de 1994, se creó por la Resolución A-61 de la OEA y con vigencia internacional desde el 5 de marzo de $1995 .{ }^{40} \mathrm{Y}$, Chile ha ratificado el tratado, en 1998, según consta en el Decreto Supremo 1640, de 11 de noviembre de $1998 .{ }^{41}$

En octavo lugar, encontramos a Convención interamericana para la eliminación de todas las formas de discriminación contra las personas con discapacidad. Adoptada en Ciudad de Guatemala, el 7 de junio de 1999, se creó por la Resolución A-65 de la OEA y con vigencia internacional desde el 14 de septiembre de $2001 .^{42}$ Y, Chile ha ratificado el tratado, en 2001, según consta en el Decreto Supremo 99, de 20 de junio de $2002.4^{43}$

En noveno lugar, encontramos a Convención interamericana contra el terrorismo. Adoptada en Bridgetown, el 3 de junio de 2002, se creó por la Resolución A-66 de la OEA y con vigencia internacional desde el 10 de julio de $2003 .{ }^{44} \mathrm{Y}$, Chile ha ratificado el tratado, en 2004, según consta en el Decreto Supremo 263, publicado el 10 de febrero de $2005,{ }^{45}$ aunque con una declaración, como sigue:

El Gobierno de Chile, sin perjuicio de reiterar su condena a todos los actos, métodos y prácticas del terrorismo, cualesquiera sea su motivación, forma o manifestación, y de expresar que continuará adoptando todas las medidas pertinentes que sean necesarias en la lucha contra dichos actos, viene en manifestar que la disposición del artículo 13 de la

40 ORGANIZACIÓN DE LOS ESTADOS AMERICANOS. Convención interamericana para prevenir, sancionar y erradicar la violencia en contra de la mujer. Resolución A-61, de 9 de junio de 1994. Disponible en: http://www.oas.org/juridico/spanish/ tratados/a-61.html Acceso en: 26 oct. 2020.

${ }^{41}$ CHILE. Decreto Supremo 1640, de 11 de noviembre de 1998. Disponible en: https://www.bcn.cl/leychile/navegar?idNorma=127037 Acceso en: 26 oct. 2020.

42 ORGANIZACIÓN DE LOS ESTADOS AMERICANOS. Convención interamericana para la eliminación de todas las formas de discriminación contra las personas con discapacidad. Resolución A-65, de 7 de junio de 1999. Disponible en: http://www.oas.org/juridico/spanish/tratados/a-65.html Acceso en: 26 oct. 2020.

43 CHILE. Decreto Supremo 99, de 25 marzo de 2002. Disponible en: https://www.bcn.cl/leychile/navegar?idNorma=199523 Acceso en: 26 oct. 2020.

${ }^{44}$ ORGANIZACIÓN DE LOS ESTADOS AMERICANOS. Convención interamericana contra el terrorismo. Resolución A-66, de 3 de junio de 2002. Disponible en: http://www.oas.org/juridico/ spanish/tratados/a-66.html Acceso en: 26 oct. 2020.

45 CHILE. Decreto Supremo 263, publicado el 10 de febrero de 2005. Disponible en: https://www.bcn.cl/leychile/navegar?idNorma $=235395$ Acceso en: 26 oct. 2020.
Convención, no menoscaba el derecho del Estado asilante de calificar, en conformidad con el derecho internacional, la naturaleza del hecho que origina la solicitud de asilo.

En décimo lugar, encontramos a la Convención interamericana sobre la protección de los derechos humanos de las personas mayores. Adoptada en Washington, D.C., el 15 de junio de 2015, se creó por la Resolución A-70 de la OEA y con vigencia internacional desde el 11 de enero de $2017 .{ }^{46} \mathrm{Y}$, Chile ha ratificado el tratado, en 2017, según consta en el Decreto Supremo 162, publicado el 7 de octubre de 2017, ${ }^{47}$ aunque con algunas declaraciones, como sigue:

La República de Chile declara que el enfoque de curso de vida será entendido como el continuo de la vida de la persona, desde el inicio de su existencia hasta la última etapa de su vida, que, condicionada por diversos factores, como el familiar, social, económico, ambiental y/o cultural, configuran su situación vital, siendo el Estado el encargado de desarrollar este enfoque en sus políticas públicas, planes y programas, con especial énfasis en la vejez.

La República de Chile declara que la identidad de género a que alude la presente Convención será entendida en armonía con lo dispuesto en su legislación nacional.

La República de Chile declara que los Artículos 5 y 18, inciso segundo, ambos en relación con el Artículo 2 de la misma Convención, no impiden, de ninguna forma, la adopción de medidas legítimas, razonables y proporcionadas, como son las que, fundadas en las exigencias ya sea del funcionamiento de una institución, o en las propias de la naturaleza del cargo o función, establecen límites de edad para desempeñar ciertos cargos o funciones públicas, por lo que no podrán considerarse como constitutivas de un acto de discriminación.

La República de Chile declara, en relación con el Artículo 11 de la Convención, que el consentimiento libre e informado en el ámbito de la salud al que ella se refiere deberá ser prestado en conformidad a los requisitos tanto formales como sustantivos y a todas las demás disposiciones aplicables en la materia vigentes en el ordenamiento jurídico chileno.

Con todo, desde el punto de vista normativo se cumple con el requisito para que los tratados referidos \begin{tabular}{l}
\hline 46 ORGANIZACIÓN DE LOS ESTADOS AMERICANOS. \\
Convención interamericana sobre la protección de los derechos \\
humanos de las personas mayores. Resolución A-70, de 15 de junio \\
de 2015. Disponible en: http://www.oas.org/es/sla/ddi/tratados_- \\
multilaterales_interamericanos_A-70_derechos_humanos_perso- \\
nas_mayores.asp Acceso en: 26 oct. 2020 . \\
${ }^{47}$ CHILE. Decreto Supremo 162,publicadoel7 de octubre de 2017.Disponi- \\
ble en: https://www.bcn.cl/leychile/navegar?idNorma=1108819 \\
Acceso en: 26 oct. 2020.
\end{tabular} 
sean parte del bloque de constitucionalidad en Chile. Todos tratan sobre derechos humanos, es decir, pactos que reconocen, crean o desarrollan derechos esenciales de la naturaleza humana. Como tratados internacionales ratificados se deben aplicar por el pacta sunt servanda y/o sumado a ello, por aplicación el artículo 5 inciso segundo de la Constitución chilena, pues han sido ratificados por Chile y se encuentran vigentes. Incluso, es posible afirmar que se trata de una verdadera política de Estado incluir a los tratados de la OEA como parte del bloque de constitucionalidad chileno. En efecto, como se pudo advertir, desde las ratificaciones de los años setenta en adelante han pasado diversos jefes de Estado y, todos mandan a cumplir con estos, cuando han sido ratificados. Sin embargo, varios de estos se han ratificado con algunas declaraciones y reservas, lo que es preciso revisar con los estándares actuales de promoción y protección los derechos humanos.

Por otro lado, es preciso tener en cuenta los tratados que Chile aún no ha ratificado y que versen sobre derechos humanos creados a propósito de la OEA. Ello, para tener en consideración propuestas de futuro y que son parte de hallazgos de investigación, que serán revisados sucintamente por la extensión y objeto de este trabajo. En efecto, entre estos, encontramos:

Por un lado, al Protocolo adicional a la Convención americana sobre derechos humanos en materia de derechos económicos, sociales y culturales. Adoptado en San Salvador, el 17 de noviembre de 1988, se creó por la Resolución A-52 de la OEA y con vigencia internacional desde el 16 de noviembre de 1999. Chile solo ha suscrito el tratado el 5 de junio de $2001 .^{48}$

Además, a la Convención americana para facilitar la asistencia en casos de desastre. Adoptada en Santiago de Chile, el 7 de junio de 1991, se creó por la Resolución A-54 de la OEA y con vigencia internacional desde el 16 de noviembre de 1996. A pesar de ser adoptada en Chile, no ha sido firmada y menos ratificada por dicho país. $^{49}$

${ }_{48}$ ORGANIZACIÓN DE LOS ESTADOS AMERICANOS. Protocolo adicional a la Convención americana sobre derechos humanos en materia de derechos económicos, sociales y culturales. Resolución A-52, de 17 de noviembre de 1988. Disponible en: http:// www.oas.org/juridico/spanish/Tratados/a-52.html Acceso en: 26 oct. 2020.

49 ORGANIZACIÓN DE LOS ESTADOS AMERICANOS. Convención americana para facilitar la asistencia en casos de desastre. Resolución A-54, de 16 de noviembre de 1996. Disponible en: http:/ / www.oas.org/juridico/spanish/tratados/a-54.html Acceso en: 26
Por otro lado, a la Convención interamericana contra el racismo, la discriminación racial y formas conexas de intolerancia. Adoptada en La Antigua, Guatemala, el 5 de mayo de 2013, se creó por la Resolución A-68 de la OEA, entrando en vigor el 11 de noviembre de 2017. Chile solo ha firmado el tratado el 22 de octubre de $2015 .{ }^{50}$

Y, finalmente a la Convención interamericana contra toda forma de discriminación e intolerancia. Adoptada en La Antigua, Guatemala, el 5 de mayo de 2013, se creó por la Resolución A-69 de la OEA, entrando en vigor el 20 de febrero de 2020. Chile solo ha firmado el tratado el 22 de octubre de $2015 .{ }^{51}$

\section{De la teoría a la práctica: inclusión de los tratados sobre derechos humanos de la OEA en el bloque de constitucionalidad chileno: su aplicación en los máximos tribunales}

El día 1 de marzo de 2018 se inauguraba el año judicial. El excelentísimo Ministro y Presidente de la Corte Suprema señor Haroldo Brito Cruz daba cuenta de la gestión del Poder Judicial exponiendo de cómo se ha cumplido el mandato y por otro lado, señalaba lo que debería hacerse para mejorar la administración de justicia. En efecto, hubo una serie de reflexiones y estadísticas relevantes para todo estudiante, litigante o académico que se dedique al Derecho. Una muy significativa, el gran número de porcentaje de causas que conoce el máximo tribunal que tratan sobre derechos humanos, ya sea provenientes del recurso de amparo, del recurso de protección, del recurso de nulidad en materia penal o por medios de impugnación originados en tutela de derechos fundamentales en el contexto de las relaciones laborales. En concreto, expresaba lo siguiente: ${ }^{52}$

oct. 2020.

${ }^{50}$ ORGANIZACIÓN DE LOS ESTADOS AMERICANOS. Convención interamericana contra el racismo, la discriminación racial y formas conexas de intolerância. Resolución A-68. Disponible en: http://www.oas.org/es/sla/ddi/tratados_multilaterales_ interamericanos_A-68_racismo.asp Acceso en: 26 oct. 2020.

51 ORGANIZACIÓN DE LOS ESTADOS AMERICANOS. Convención interamericana contra toda forma de discriminación e intolerância. Resolución A-69. Disponible en: http://www.oas.org/ es/sla/ddi/tratados_multilaterales_interamericanos_A-69_discriminacion_intolerancia_firmas.asp Acceso en: 26 oct. 2020.

${ }^{52}$ CHILE. Ministerio del Interior y Seguridad Pública. Cuenta 
Dejando a un lado las apelaciones de los recursos de protección contra Isapres, que siguen su tendencia histórica y representan un importante número de casos -más del 70\% del total-, cabe también preguntarse qué asuntos conoce este tribunal. La respuesta es significativa: desarrollamos un rol orientado a la aplicación directa de la Constitución, ya que más de un tercio de lo que conocemos tiene como origen una acción constitucional, tales como el recurso de amparo $(20 \%)$ o de protección $(16 \%)$, sin considerar los recursos en lo penal que se fundamentan en normas de esta clase, ni las acciones de tutela de derechos fundamentales en lo laboral.

Aquello significa que la administración de justicia necesita estar al día en materia de derechos humanos. Es así como no sólo magistrados y funcionarios del poder judicial deben considerar normas protectoras de derechos fundamentales, sino que también, uno de los principales auxiliares de justicia, los abogados, pueden y deben utilizarlas en sus argumentaciones para una mejor resolución del caso. El mismo Presidente de la Excelentísima Corte en su discurso inaugural de 2018 indicaba que se propone incorporar como política la perspectiva de derechos humanos en la resolución de los asuntos. ${ }^{53}$

Entonces, como política de administración de justicia se considera aplicar la normativa sobre derechos humanos en las resoluciones judiciales. En los siguientes párrafos se dan muestras de la aplicación de cada uno de los tratados internacionales referidos en el punto anterior para determinar que si son o no parte del bloque de constitucionalidad en Chile. Es decir, veremos como del texto positivo trascienden a la aplicación práctica en tribunales de justicia.

Así, en primer y segundo lugar, se analiza lo pertinente en relación con la Convención interamericana sobre concesión de los derechos políticos a la mujer, y, la Convención interamericana sobre la concesión de derechos civiles a la mujer. Haciendo una búsqueda exhaustiva en el portal del Poder Judicial ${ }^{54}$ y en otros

Pública Presidencia Corte Suprema 2018: discurso del Presidente de la Corte Suprema señor Haroldo Brito Cruz. 2018. Disponible en: http://www.diariooficial.interior.gob.cl/publicacion es/2018/04/06/42025/01/1370510.pdf Acceso en: 26 oct. 2020.

53 CHILE. Ministerio del Interior y Seguridad Pública. Cuenta Pública Presidencia Corte Suprema 2018: discurso del Presidente de la Corte Suprema señor Haroldo Brito Cruz. 2018. Disponible en: http://www.diariooficial.interior.gob.cl/publicacion es/2018/04/06/42025/01/1370510.pdf Acceso en: 26 oct. 2020.

${ }^{54}$ CHILE. Poder Judicial. Bases jurisprudenciales. Disponible en: http://basejurisprudencial.poderjudicial.cl/ Acceso en: 26 oct. 2020. medios electrónicos, no se encontró jurisprudencia que cite expresamente a estos tratados. Sin embargo, ello no quiere decir que los derechos y principios consignados en estos no se tengan en consideración. De hecho, la normativa se ha ido modificando en atención a estos y así sigue haciéndose inclusive al 2020 (como con la Ley 21264, de 11 de septiembre de $2020,{ }^{55}$ que suprime un impedimento de rango legal para contraer segundas nupcias a mujeres en determinados casos, restricción que no tenía el marido). No obstante, a lo anterior, los tribunales sí han considerado expresamente en sus resoluciones a la Convención interamericana para prevenir, sancionar y erradicar la violencia en contra de la mujer, como se revisará más adelante, que es un tratado afín con los dos citados.

En tercer lugar, revisemos entonces un caso sobre la aplicación de la Convención americana sobre derechos humanos. Se presenta un recurso de amparo en contra del Juzgado de Cobranza Laboral y Previsional de Santiago y en contra de Policía de Investigaciones de Chile. Se reclama sobre la dictación y mantención en vigencia de la resolución del tribunal en $2008,{ }^{56}$ en la cual se dispuso orden de arresto y arraigo, en contra del eventual afectado, con motivo al impago de obligaciones previsionales (imposiciones, cotizaciones). La deuda asciende a $\$ 1.146 .505$.

Se rechaza el amparo en primera instancia, por la Ilustrísima Corte de Apelaciones de Santiago, ${ }^{57}$ y se acoge en segunda instancia, por la Excelentísima Corte Suprema. ${ }^{58}$ Se establece por el máximo tribunal que, no puede equipararse la obligación de pago de cotizaciones a deberes alimenticios. Así, teniendo presente que el artículo 7 número 7 del Pacto de San José de Costa Rica, concretamente que "Nadie será detenido por deuda. Este principio no limita los mandatos de autoridad judicial competente dictados por incumplimiento de

55 CHILE. Ley 21.264, de 11 de septiembre de 2020. Disponible en: https://www.bcn.cl/leychile/navegar?idNorma=1149335\&tipoVer sion $=0$ Acceso en: 26 oct. 2020.

${ }^{56}$ CHILE. Juzgado de Cobranza Laboral y Previsional de Santiago, RIT: A-11407-2006, Ejec. Previsional Antiguo, Resolución de 7 de abril de 2008. Disponible en: https://cobranza.pjud.cl/SITCOPORWEB/InicioAplicacion.do Acceso en: 26 oct. 2020.

57 CHILE. Ilustrísima Corte de Apelaciones de Santiago, Rol 1447-2018, Amparo, Sentencia de 21 de junio de 2018. Disponible en: https:/ / corte. pjud.cl/SITCORTEPORTAL/ Acceso en: 26 oct. 2020.

58 CHILE. Excelentísima Corte Suprema, Rol 15023-2018, Apelación Amparo, Sentencia de 28 de junio de 2018. Disponible en: https://suprema.pjud.cl/SITSUPPORWEB/InicioAplicacion.do Acceso en: 26 oct. 2020. 
los deberes alimentarios", contiene una regla general, no constituyéndose en la excepción el caso, por lo que procede dejar en libertad al afecto.

La sentencia fue acordada contra el voto de dos Ministros, confirmando por los propios fundamentos de la resolución apelada. ${ }^{59}$ Ello, pues la orden de arresto reclamada ha sido expedida por autoridad facultada por la ley para hacerlo, en uno de los casos previstos en la ley, con sujeción a las formalidades que la misma establece, y habiendo mérito bastante que la justifica (se desprende que subsiste una deuda por cotizaciones previsionales a pagar por el amparado, y no habría certeza de que éstas hayan sido pagadas totalmente a la fecha) debe desestimarse el amparo.

En cuarto lugar, revisemos entonces un caso sobre la Convención interamericana para prevenir y sancionar la tortura. En una causa seguida ante un Tribunal Oral en Lo Penal se dictó sentencia definitiva ${ }^{60}$ condenándose a dos personas a la pena de cinco años y un día de presidio mayor en su grado mínimo más accesorias, como autores del delito de homicidio.

En contra la sentencia, la defensa de los condenados interpusieron recursos de nulidad. Ambos recursos, son similares, pero coinciden, en general, sobre el siguiente motivo de nulidad que es de relevancia para el presente trabajo. En efecto, reclaman en relación con lo contemplado en la letra a) del artículo 373 del Código Procesal Penal, porque tanto durante la tramitación del juicio como en el pronunciamiento de la sentencia se infringieron sustancialmente derechos o garantías aseguradas por la Carta Fundamental y los tratados internacionales vigentes ratificados por Chile (entre otros citan precisamente a la Convención Interamericana para Prevenir y Sancionar la Tortura). Así, en concreto, las defensas alegaron haberse ejercido apremios ilegítimos, consistentes en una permanencia de más de 8 horas en dependencias de la policía, tiempo durante el cual se interrogó reiteradamente a los detenidos, se les prohibió comunicarse tanto entre ellos, familiares y como con terceros. Además, se los mantuvo mirando hacia un

\footnotetext{
59 CHILE. Excelentísima Corte Suprema, Rol 15023-2018, Apelación Amparo, Sentencia de 28 de junio de 2018. Disponible en: https://suprema.pjud.cl/SITSUPPORWEB/InicioAplicacion.do Acceso en: 26 oct. 2020.

${ }^{60}$ CHILE. Tribunal Oral en lo Penal de Viña del Mar, RIT: 45-2004, Sentencia de 16 de diciembre de 2004. Disponible en: https:/ / reformaprocesal.pjud.cl/ConsultaCausasJsfWeb/page/panelConsultaCausas. jsf Acceso en: 26 oct. 2020.
}

muro mientras no eran interrogados. Y, que los policías guiaron y ordenaron las declaraciones de familiares de los detenidos.

Se rechaza el recurso de nulidad. ${ }^{61} \mathrm{El}$ tribunal establece que el artículo 373 letra a) del Código Procesal Penal dispone que,

Procederá la declaración de nulidad del juicio oral
y de la sentencia: a) Cuando en la tramitación o
en el pronunciamiento de la sentencia se hubieren
infringido sustancialmente derechos o garantías
asegurados por la Constitución o por tratados
internacionales ratificados por Chile, que se
encuentren vigentes.

Norma de la que se infiere que el recurso de nulidad no puede prosperar cuando los vicios denunciados han tenido lugar antes de la apertura del juicio oral, como ocurre en este caso. Es decir, tiene presente a los tratados, pero ante vulneraciones habría que utilizar las herramientas procesales acorde al estado y oportunidad del proceso.

En quinto lugar, revisemos un caso sobre la aplicación del Protocolo a la Convención Americana sobre derechos humanos relativos a la abolición de la pena de muerte. Haciendo una búsqueda exhaustiva en el portal del Poder Judicial ${ }^{62}$ y en otros medios electrónicos, no se encontró jurisprudencia que cite expresamente a estos tratados. Sin embargo, ello no quiere decir que los derechos y principios consignados en estos no se tengan en consideración. De hecho, la normativa que contemplaba la pena de muerte ha sido derogada, según dispone la Ley 19734, de 5 de junio 2001. ${ }^{63}$ Sin embargo, aún queda vigente en la legislación la pena capital del Código de Justicia Militar, concretamente en los artículos 235 y siguientes. ${ }^{64}$ Sin embargo, afortunadamente no ha tenido que ser aplicada por los tribunales chilenos al menos de forma posterior a la ratificación del tratado.

En sexto lugar, revisemos entonces un caso sobre la aplicación de la Convención interamericana sobre de\begin{tabular}{l}
\hline${ }^{61}$ CHILE. Excelentísima Corte Suprema, Rol 3-2005, Criminal, Sentencia \\
de 14 de abril de 2005. Disponible en: https://suprema.pjud.cl/SIT- \\
SUPPORWEB/InicioAplicacion.do Acceso en: 26 oct. 2020. \\
${ }^{62}$ CHILE. Poder Judicial. Bases jurisprudenciales. Disponible en: \\
http://basejurisprudencial.poderjudicial.cl/ Acceso en: 26 oct. \\
2020. \\
${ }^{63}$ CHILE. Ley 19734, de 5 de junio 2001. Disponible en: https:// \\
www.bcn.cl/leychile/navegar?idNorma=186161 Acceso en: 26 oct. \\
2020. \\
${ }^{64}$ CHILE. Código de Justicia Militar, de 19 de diciembre de 1944. Dis- \\
ponible en: https://www.bcn.cl/leychile/navegar?idNorma=18914 \\
Acceso en: 26 oct. 2020 .
\end{tabular} 
saparición forzada de personas. Un grupo de mujeres demandan al Fisco de Chile por el pago de una indemnización por el daño moral sufrido. Ellas son la cónyuge e hijas de una persona detenida en el año 1978 en una Comisaría de Carabineros, cuando intentaba asilarse en la Embajada de un país extranjero en Chile. En efecto, la persona detenida fue trasladada a la Dirección de Inteligencia del Ejército, permaneciendo desaparecida hasta el presente. Así, el juez a quo rechaza la demanda, acogiendo excepción de prescripción. Ante ello, se presenta recurso de apelación con el que es acogida la acción, afirmándose que las conductas acreditadas en autos son imprescriptibles, a la luz de los instrumentos internacionales suscritos, ratificados y vigentes en Chile. Consecuencia de ello, la excepción de prescripción debe rechazarse. ${ }^{65}$ Por ello, el Fisco presenta recurso de casación en el fondo.

Se acoge el recurso de casación en el fondo, por lo que se rechaza la demanda. ${ }^{66}$ Se establece que en los autos se ha ejercido una acción de contenido patrimonial cuya finalidad es hacer efectiva la responsabilidad extracontractual del Estado, por lo que cabe aplicar las normas del Código Civil. Asimismo, que no existe norma internacional incorporada a Chile que establezca la imprescriptibilidad genérica de las acciones orientadas a obtener el reconocimiento de la responsabilidad extracontractual del Estado. Sin embargo, hubo dos votos en contra, por los que se rechaza el recurso de casación. ${ }^{67}$ Así, la disidencia establece que los jueces de la instancia no han incurrido en error de derecho al no dar aplicación a las normas del Código Civil, sino a las normas constitucionales y los tratados internacionales ratificados por Chile que regulan el tema de la responsabilidad estatal. Ello, pues afirmar que las únicas reglas que existen en nuestro país para regular la responsabilidad del Estado son las contenidas en el Código Civil, importa negar validez y eficacia a normas jurídicas de carácter constitucional, administrativo e internacional que ya han sido aplicadas por los tribunales en materia de violación de derechos humanos.

${ }_{65}$ CHILE. Ilustrísima Corte de Apelaciones de Santiago, Rol 3319-2007. ${ }^{66}$ CHILE. Excelentísima Corte Suprema, Rol 8593-2009, Casación Fondo, Sentencia de 21 de agosto de 2009. Disponible en: https:// suprema.pjud. cl/SITSUPPORWEB/InicioAplicacion.do Acceso en: 26 oct. 2020. ${ }^{67}$ CHILE. Excelentísima Corte Suprema, Rol 8593-2009, Casación Fondo, Sentencia de 21 de agosto de 2009. Disponible en: https:// suprema.pjud. cl/SITSUPPORWEB/InicioAplicacion.do Acceso en: 26 oct. 2020.
En séptimo lugar, revisemos entonces un caso sobre la aplicación de la Convención interamericana para prevenir, sancionar y erradicar la violencia en contra de la mujer. Se presenta un recurso de protección por una persona en contra de controladores de una revista digital por vulnerar su vida privada e imagen. Ello, por haberse publicado en un portal electrónico un reportaje sobre distintos episodios de violencia sufridos por mujeres, en el que el recurrente aparecería como responsable. La recurrida hace valer antecedentes sobre el recurso, pidiendo su rechazo, básicamente porque el reportaje cuestionado es sobre un asunto de interés público. Agrega que el recurrente tuvo oportunidad de efectuar su derecho a réplica al mencionado reportaje y no lo hizo; además, refiere que registra dos denuncias en el Ministerio Público, por maltrato habitual, abuso sexual y violación.

Se rechaza el recurso de protección por la ilustrísima Corte de Apelaciones de Santiago, ${ }^{68}$ lo que es confirmado por la Excelentísima Corte Suprema. ${ }^{69}$ Se establece que la publicación aludida no invade un aspecto de la vida privada del recurrente, pues implicaría ignorar el avance y logro que ha tenido la tutela efectiva de la comunidad internacional en el reconocimiento de derechos en favor de la mujer que otrora estaban vedados, en cuanto al maltrato, violencia doméstica y otras conductas vejatorias, en el plano privado. Así, por ejemplo, Chile ha suscrito determinados instrumentos internacionales (Convención Interamericana para Prevenir, Sancionar y Erradicar la Violencia contra la Mujer, en 1996, comúnmente conocida como la "Convención de Belém Do Pará", efectuada en Brasil). Por ello, la publicación está resguardada con el legítimo ejercicio del periodismo.

Por otra parte, se determina además que lo anterior no significa desatender la garantía del artículo $19 \mathrm{~N}^{\circ} 4$ de la Constitución Política de la República (honra de la persona, privacidad, datos personales y jurisprudencialmente derecho a la imagen). Sólo que existen en la legislación otras formas de hacer efectiva su tutela, habida cuenta de la situación de conflicto de garantías que

68 CHILE. Ilustrísima Corte de Apelaciones de Santiago, Rol 79039-2017, Protección, Sentencia de 5 de febrero de 2018. Disponible en: https:/ / corte.pjud.cl/SITCORTEPORTAL/ Acceso en: 26 oct. 2020.

69 CHILE. Excelentísima Corte Suprema, Rol 3019-2018, Apelación Protección, Sentencia de 27 de marzo de 2018. Disponible en: https://suprema.pjud.cl/SITSUPPORWEB/InicioAplicacion.do Acceso en: 26 oct. 2020 
presenta este caso. La contracara se da especialmente en relación con el $19 \mathrm{~N}^{\circ} 12$, libertad de emitir opinión y la de informar, sin censura previa, en cualquier forma $y$ por cualquier medio.

En octavo lugar, revisemos un caso sobre la aplicación de la Convención interamericana para la eliminación de todas las formas de discriminación contra las personas con discapacidad. Se presenta una demanda en virtud de la ley 20.422, que Establece Normas sobre Igualdad de Oportunidades e Inclusión Social de Personas con Discapacidad, en contra del Metro de Santiago. El objeto de la litis radicaba en que si al 19 de mayo 2016 la actora, quien representaba una discapacidad física del 70\% (debía movilizarse en silla de ruedas eléctrica), fue objeto de un trato discriminatorio a raíz de que la estación de Metro Santa Isabel no contaba con medidas de accesibilidad apropiadas. Así, en el día indicado, ante la presencia de un supuesto artefacto explosivo, los pasajeros fueron evacuados del tren y de la estación citada, pero la actora fue tratada en forma distinta de los demás, porque atendida su discapacidad, debió permanecer en el lugar durante una hora hasta que se restituyó el servicio, debido a que la estación no contaba con salva escaleras.

Se rechaza la demanda en Primera Instancia $\left(29^{\circ} \mathrm{Ju}-\right.$ zgado Civil de Santiago) ${ }^{70}$ y se confirma en alzada (Ilustrísima Corte de Apelaciones de Santiago). ${ }^{71}$ Se establece que la obligación consagrada en el artículo 28 de la Ley 20.422, no era exigible a la época de ocurrencia de los hechos, pues la modificación a la ley fue publicada el 23 de mayo de 2018.

Sin embargo, se presenta recurso de casación, lo que dio oportunidad para invalidar de oficio la sentencia recurrida y se redacta una sentencia de reemplazo por la Excelentísima Corte Suprema. ${ }^{72}$ Se afirma que el caso también era posible resolverlo con normativa vigente al momento de los hechos, o más bien, de la propia Ley 19.284, y se recurrió a la disposición más restrictiva, la de la actual ley, siendo pertinente la más antigua. En la

\footnotetext{
70 CHILE. Décimo Noveno Juzgado Civil de Santiago, Rol C-20679-2016, Sentencia de 13 de marzo de 2017. Disponible en: https:// civil.pjud.cl/ CIVILPORWEB/ Acceso en: 26 oct. 2020.

${ }^{71}$ CHILE. Ilustrísima Corte de Apelaciones de Santiago, Rol 5022-2017, Civil, Sentencia de 31 de agosto de 2017. Disponible en: https://corte. pjud.cl/SITCORTEPORTAL/ Acceso en: 26 oct. 2020.

${ }_{72}$ CHILE. Excelentísima Corte Suprema, Rol 41388-2017, Casación Fondo, Sentencia de 25 de julio de 2018. Disponible en: https://suprema. pjud.cl/SITSUPPORWEB/InicioAplicacion.do Acceso en: 26 oct. 2020.
}

misma idea a preceptos internacionales como los de la Convención Interamericana para la Eliminación de Todas las Formas de Discriminación contra las Personas con Discapacidad, publicada en el Diario Oficial de 20 de junio de 2002. Por ello, al demostrarse y reconocerse en autos una serie de irregularidades quedan de manifiesto discriminaciones arbitrarias en contra de la actora.

En noveno lugar, revisemos un caso sobre la aplicación de la Convención interamericana contra el terrorismo. Una persona recurre de protección en contra de un Banco por cerrar unilateralmente su cuenta corriente de la que es titular, reclamando que se vulneraria las garantías de los numerales 21 y 24 del artículo 19 de la Constitución Política de la República. A su turno, la institución financiera alude a que hizo ejercicio de facultades que le otorga la legislación, concretamente ya que va en contra de sus políticas internas, que son consecuencia de las directrices de la Superintendencia de Bancos e Instituciones Financiera, contenidas en el Capítulo 1-14, sobre prevención de lavado de activos y del financiamiento del terrorismo (así, encuadrarían los movimientos de la cuenta bancaria en operaciones inusuales o sospechosas, como aquellas que "carecen de justificación económica o jurídica aparente”). Además, a que el contrato de cuenta corriente es de naturaleza "intuito personae", lo que habilita a ambos contratantes a ponerle término unilateralmente.

Ante ello, la Ilustrísima Corte de Apelaciones de Puerto Montt rechaza el recurso, ${ }^{73}$ estableciendo que no es la magistratura indicada para conocer de la controversia, ya que no se vislumbra la existencia de un acto ilegal o arbitrario que sea vulneratorio de derechos fundamentales, toda vez que lo disputado se refiere a la acreditación de los supuestos que habilitan a una de las partes a resolver un contrato, materia que por ser de lato conocimiento está entregada a los tribunales con competencia civil y que da cuenta que el derecho que invoca el recurrente no reviste el carácter de indubitado. Por ello, se apela del fallo por el recurrente.

Así, la excelentísima Corte Suprema reproduce la sentencia recurrida, con excepción de sus considerandos que conforman la ratio decidendi del fallo. ${ }^{74}$ En efecto,

\footnotetext{
73 CHILE. Ilustrísima Corte de Apelaciones de Puerto Montt, Rol 207002017, Protección, Sentencia de 21 de abril de 2017. Disponible en: https://corte.pjud.cl/SITCORTEPORTAL/ Acceso en: 26 oct. 2020.

${ }^{74}$ CHILE. Excelentísima Corte Suprema, Rol 18161-2017, Apelación Protección, Sentencia de 6 de julio de 2017. Disponible en: https://suprema.pjud.cl/SITSUPPORWEB/InicioAplicacion.do Acceso en:
} 
resuelve rechazar el recurso de protección, puesto que no se vislumbra acto ilegal o arbitrario, sino simplemente el ejercicio por parte del recurrido (el banco) de las facultades que le son propias en el desarrollo de su actividad.

En décimo lugar, revisemos un caso sobre la aplicación de la Convención interamericana sobre la protección de los derechos humanos de las personas mayores. Se interpone un recurso de protección en contra del ministro en visita extraordinaria don Mario Carrroza Espinosa, para que se deje sin efecto resolución de 11 de septiembre de 2017, que incidiría en los autos Rol 852010, caratulado “Episodio Leandro Arratia Reyes". En dichos autos, se condena por homicidio calificado, pena que se cumple en el centro penitenciario Punta Peuco. Posteriormente, se solicitó al juez de primer grado el cumplimiento de la pena privativa de libertad en el domicilio particular del condenado (persona mayor de edad, 71 años), lo que fue negado y no apelado por el recurrente.

Se rechaza el recurso de protección ante la Ilustrísima Corte de Apelaciones de Santiago, ${ }^{75}$ lo que es confirmado por la Excelentísima Corte Suprema. ${ }^{76}$ Por un lado, en cuanto a la forma, habiendo tutela judicial en el caso (Rol 85-2010), debió reclamar conforme al artículo 74 bis del Código de Procedimiento Penal, siendo la vía idónea el recurso de apelación. Por otro lado, en cuanto al fondo, debe negarse la acción, puesto que no hay normas imperativas (nacionales) o estándares internacionales (como la Convención Interamericana sobre la Protección de los Derechos de las Personas Mayores) que establezcan que el simple paso del tiempo o la vejez autorice a que las personas condenadas a penas privativas de libertad puedan cumplir la pena impuesta en régimen domiciliario bajo la tutela familiar.

26 oct. 2020.

75 CHILE. Ilustrísima Corte de Apelaciones de Santiago, Rol 70074-2017, Protección, Sentencia de 21 de diciembre de 2017. Disponible en: https:/ / corte.pjud.cl/SITCORTEPORTAL/ Acceso en: 26 oct. 2020.

76 CHILE. Excelentísima Corte Suprema, Rol 843-2018, Apelación Protección, Sentencia de 19 de marzo de 2018. Disponible en: https:/ / suprema. pjud.cl/SITSUPPORWEB/InicioAplicacion.do Acceso en: 26 oct. 2020 .
Sin embargo, se redacta un voto particular suscrito por dos Ministros. ${ }^{77}$ Se hace imprescindible traer a colación los instrumentos jurídicos existentes como tratados y convenios, que tratan el tema en materia de derechos humanos de las personas mayores y de los cuales Chile es parte, buscando la armonía con el derecho interno. Sin embargo, siendo partidarios de acoger el recurso, pero sólo a contar de los 75 años cumplidos (teniendo como referencias los textos normativos relacionados con la edad avanzada de las personas). De lo contrario, implica innovar en una materia sobre la cual no existe por ahora remedio legislativo.

\section{Conclusiones: Hasta dónde se ha avanzado y qué queda por hacer}

Ya se ha hecho el recorrido haciéndose preciso recordar el objetivo general del presente trabajo, al preguntarse si son parte o no del bloque de constitucionalidad los principales tratados internacionales sobre derechos humanos de la OEA en el Estado de Chile. En efecto, la respuesta es un sí categórico. Ello, según como se ha respaldado con el desarrollo de los objetivos específicos del presente texto. Es decir, hay argumentos de doctrina, normativa y jurisprudencia que avala la postura del bloque de constitucionalidad. Es positivo, dado que abre un abanico de derechos fundamentales para los habitantes de la Nación. Si están en el texto positivo es un aporte, pero sí además se aplican en tribunales de justicia es un avance también en el fortalecimiento del Estado de Derecho chileno. Además, ello toma especial relevancia para el proceso constituyente que está viviendo Chile, en el sentido de considerar estos tratados, este bloque de constitucionalidad como un límite, pero al mismo tiempo una guía en la redacción de una Nueva Constitución. Es decir, el mismo poder constituyente se autolimita para no afectar derechos humanos, inclusive ante la posibilidad de refundación del Estado.

Sin embargo, hay tratados que aún no han sido ratificados y algunos ni siquiera firmados por Chile que ver-

7 CHILE. Excelentísima Corte Suprema, Rol 843-2018, Apelación Protección, Sentencia de 19 de marzo de 2018. Disponible en: https:/ / suprema. pjud.cl/SITSUPPORWEB/InicioAplicacion.do Acceso en: 26 oct. 2020. 
san sobre derechos humanos y que han sido creados a propósito de la OEA. Son pocos, aunque en cierta forma algunos de estos pueden ser suplidos en cierto grado por otros, como aquellos que versan sobre no discriminación. Por ejemplo, tanto en la Constitución chilena y en los tratados que ha firmado y ratificado encontramos diversas normas y principios en favor de la igualdad y prohibición de la discriminación. No obstante, a ello, hay tratados que hace falta incorporar, dado que desarrollan otros derechos que difícilmente se sustituyen o reemplazan, estos se encuentran en el tratado denominado Protocolo adicional a la Convención americana sobre derechos humanos en materia de derechos económicos, sociales y culturales, conocido como el Protocolo de San Salvador, que Chile aún no ha ratificado, o, a lo menos integrarlo con alguna declaración o reserva como se ha hecho con otros tratados, siempre y cuando no se afecte con la esencia de la normativa internacional de derechos humanos.

Asimismo, para mejorar el bloque de constitucionalidad a propósito de los tratados de la OEA que ha ratificado Chile y que se encuentran vigentes, que se han estudiado y evidenciado con aplicación de jurisprudencia, es preciso que se revise aquellos que han sido integrados con declaraciones o reservas. Algunas están íntimamente relacionadas con derechos humanos elementales, como con la aplicación excepcional de pena de muerte, que es menester eliminar para así robustecer aún más la promoción y protección de los derechos humanos en Chile. Si bien, no se ha aplicado la pena de muerte desde que entró en vigor y ratificada la normativa internacional, es un acto de promoción de los derechos humanos que es menester realizar. Con ello se va profundizando en una perspectiva de derechos humanos y, especialmente, la visión y el compromiso como país hacia con estos derechos, que puede aportar a nivel regional, inclusive a nivel global en favor con los derechos esenciales, generando buenas prácticas al efecto.

No obstante, a todo lo anterior, y, a pesar de la comprobación del bloque de constitucionalidad chileno sumando a los principales tratados de la OEA, se evidencia que en ciertos casos su aplicación no es uniforme en los tribunales de justicia, generando votos de mayoría y disidentes. En ocasiones con mayoría a favor del recurrente y en la misma línea de aplicación del tratado y viceversa. Este punto es relevante para un efectivo bloque de constitucionalidad que incorpore los tratados internacionales. Ello, en el sentido de no obstaculizar su aplicación utilizando derecho interno, especialmente cuando se basa en normas de rango legal y no constitucional. En otras palabras, es preciso acentuar como política en la administración de justicia la perspectiva de derechos humanos en la resolución de los casos, tal como indicaba el Presidente de la Excelentísima Corte Suprema en 2018. Ello cobra gran importancia cuando los tribunales conocen por distintas vías y materias en un rol orientado a la aplicación directa de la Constitución.

\section{Referencias}

CHILE. Código de Justicia Militar, de 19 de diciembre de 1944. Disponible en: https://www.bcn.cl/leychile/ navegar?idNorma=18914 Acceso en: 26 oct. 2020.

CHILE. Décimo Noveno Jurgado Civil de Santiago, Rol C-20679-2016, Sentencia de 13 de marzo de 2017. Disponible en: https://civil.pjud.cl/CIVILPORWEB/ Acceso en: 26 oct. 2020.

CHILE. Decreto 100. Fija el texto refundido, coordinado y sistematizado de la Constitucion Politica de la Republica de Chile. Disponible en: https://www.bcn.cl/ leychile/navegar?idNorma $=242302$ Acceso en: 26 oct. 2020.

CHILE. Decreto Supremo 12, de 24 de febrero de 2010. Disponible en: https://www.leychile.cl/ Navegar?idNorma=1011251 Acceso en: 26 oct. 2020.

CHILE. Decreto Supremo 162, publicado el 7 de octubre de 2017. Disponible en: https://www.bcn.cl/leychile/ navegar?idNorma=1108819 Acceso en: 26 oct. 2020.

CHILE. Decreto Supremo 1640, de 11 de noviembre de 1998. Disponible en: https://www.bcn.cl/leychile/ navegar?idNorma=127037 Acceso en: 26 oct. 2020.

CHILE. Decreto Supremo 252, de 16 de diciembre de 2008. Disponible en: https://www.bcn.cl/leychile/ navegar?idNorma=283525 Acceso en: 26 oct. 2020.

CHILE. Decreto Supremo 263, publicado el 10 de febrero de 2005. Disponible en: https://www.bcn.cl/leychile/ navegar?idNorma=235395 Acceso en: 26 oct. 2020 .

CHILE. Decreto Supremo 309, de 26 de mayo de 1975. Disponible en: https://www.bcn.cl/leychile/ navegar?idNorma=400857 Acceso en: 26 oct. 2020. 
CHILE. Decreto Supremo 310, de 26 de mayo de 1975. Disponible en: https://www.bcn.cl/leychile/ navegar?idNorma=400628 Acceso en: 26 oct. 2020.

CHILE. Decreto Supremo 381. Promulga la Convencion sobre el Derecho de los Tratados y su anexo, suscrita por el Gobierno de Chile em Viena, el 23 de mayo de 1969. Disponible en: https://www.bcn.cl/leychile/nav egar? $i d$ Norma $=12889$ \&idParte $=0 \& i d$ Version $=$ Acceso en: 26 oct. 2020.

CHILE. Decreto Supremo 809, de 26 de noviembre de 1988. Disponible en: https://www.bcn.cl/leychile/navegar?id Norma $=15728 \&$ idParte $=0$ \&idVersion $=$ Acceso en: 26 oct. 2020.

CHILE. Decreto Supremo 873, de 5 de enero de 1991. Disponible en: https://www.bcn.cl/leychile/ navegar?idNorma=16022 Acceso en: 26 oct. 2020 .

CHILE. Decreto Supremo 99, de 25 marzo de 2002. Disponible en: https://www.bcn.cl/leychile/ navegar?idNorma=199523 Acceso en: 26 oct. 2020.

CHILE. Excelentísima Corte Suprema, Rol 15023-2018, Apelación Amparo, Sentencia de 28 de junio de 2018. Disponible en: https://suprema.pjud.cl/SITSUPPORWEB/ InicioAplicacion.do Acceso en: 26 oct. 2020.

CHILE. Excelentísima Corte Suprema, Rol 18161-2017, Apelación Protección, Sentencia de 6 de julio de 2017. Disponible en: https://suprema.pjud.cl/SITSUPPORWEB/ InicioAplicacion.do Acceso en: 26 oct. 2020.

CHILE. Excelentísima Corte Suprema, Rol 3019-2018, Apelación Protección, Sentencia de 27 de marzo de 2018. Disponible en: https://suprema.pjud.cl/SITSUPPORWEB/ InicioAplicacion.do Acceso en: 26 oct. 2020.

CHILE. Excelentísima Corte Suprema, Rol 3-2005, Criminal, Sentencia de 14 de abril de 2005. Disponible en: https:// suprema.pjud.cl/SITSUPPORWEB/InicioAplicacion. do Acceso en: 26 oct. 2020.

CHILE. Excelentísima Corte Suprema, Rol 41388-2017, Casación Fondo, Sentencia de 25 de julio de 2018. Disponible en: https:// suprema.pjud.cl/SITSUPPORWEB/InicioAplicacion.do Acceso en: 26 oct. 2020.

CHILE. Excelentísima Corte Suprema, Rol 843-2018, Apelación Protección, Sentencia de 19 de marzo de 2018. Disponible en: https://suprema.pjud.cl/SITSUPPORWEB/ InicioAplicacion.do Acceso en: 26 oct. 2020.
CHILE. Excelentísima Corte Suprema, Rol 8593-2009, Casación Fondo, Sentencia de 21 de agosto de 2009. Disponible en: https://suprema.pjud.cl/SITSUPPORWEB/InicioAplicacion.do Acceso en: 26 oct. 2020.

CHILE. Historia de la Ley: Constitución Política de la República de Chile de 1980. Disponible en: http:// www.leychile.cl/Navegar/scripts/obtienearchivo?id=re cursoslegales/10221.3/44169/2/HLArt5CPR.pdf Acceso en: 26 oct. 2020 .

CHILE. Ilustrísima Corte de Apelaciones de Puerto Montt, Rol 20700-2017, Protección, Sentencia de 21 de abril de 2017. Disponible en: https:/ / corte.pjud.cl/SITCORTEPORTAL/ Acceso en: 26 oct. 2020.

CHILE. Ilustrísima Corte de Apelaciones de Santiago, Rol 1447-2018, Amparo, Sentencia de 21 de junio de 2018. Disponible en: https://corte.pjud.cl/SITCORTEPORTAL/ Acceso en: 26 oct. 2020.

CHILE. Ilustrísima Corte de Apelaciones de Santiago, Rol 3319-2007.

CHILE. Ilustrísima Corte de Apelaciones de Santiago, Rol 5022-2017, Civil, Sentencia de 31 de agosto de 2017. Disponible en: https://corte.pjud.cl/SITCORTEPORTAL/ Acceso en: 26 oct. 2020.

CHILE. Ilustrísima Corte de Apelaciones de Santiago, Rol 70074-2017, Protección, Sentencia de 21 de diciembre de 2017. Disponible en: https://corte.pjud.cl/SITCORTEPORTAL/ Acceso en: 26 oct. 2020.

CHILE. Ilustrísima Corte de Apelaciones de Santiago, Rol 79039-2017, Protección, Sentencia de 5 de febrero de 2018. Disponible en: https:// corte.pjud.cl/SITCORTEPORTAL/ Acceso en: 26 oct. 2020.

CHILE. Juzgado de Cobranza Laboral y Previsional de Santiago, RIT: A-11407-2006, Ejec. Previsional Antiguo, Resolución de 7 de abril de 2008. Disponible en: https://cobranza.pjud.cl/SITCOPORWEB/InicioAplicacion.do Acceso en: 26 oct. 2020.

CHILE. Ley 19734, de 5 de junio 2001. Disponible en: https://www.bcn.cl/leychile/ navegar?idNorma=186161 Acceso en: 26 oct. 2020.

CHILE. Ley 21.264, de 11 de septiembre de 2020. Disponible en: https://www.bcn.cl/leychile/navegar?idNorma $=1149335$ \&tipoVersion=0 Acceso en: 26 oct. 2020 .

CHILE. Ministerio del Interior y Seguridad Pública. Cuenta Pública Presidencia Corte Suprema 2018: di- 
scurso del Presidente de la Corte Suprema señor Haroldo Brito Cruz. 2018. Disponible en: http:// www.diariooficial.interior.gob.cl/publicaciones/2018/04/06/42025/01/1370510.pdf Acceso en: 26 oct. 2020 .

CHILE. Poder Judicial. Bases jurisprudenciales. Disponible en: http://basejurisprudencial.poderjudicial.cl/ Acceso en: 26 oct. 2020.

CHILE. Tribunal Oral en lo Penal de Viña del Mar, RIT: 45-2004, Sentencia de 16 de diciembre de 2004. Disponible en: https://reformaprocesal.pjud.cl/ConsultaCausasjsfWeb/page/panelConsultaCausas.jsf Acceso en: 26 oct. 2020.

CUMPLIDO CERECEDA, Francisco. La reforma constitucional de 1989 al inciso $2^{\circ}$ del artículo $5^{\circ}$ de la Constitución: sentido y alcance de la reforma. Doctrina y Jurisprudencia. Ius et Praxis, Talca, v. 9, n 1, p. 365-374, 2003.

DÍAZ FUENZALIDA, Juan Pablo. ¿Son parte del bloque de constitucionalidad los principales tratados internacionales de derechos humanos de la ONU en Chile? Del texto positivo a la aplicación en tribunales de justicia. Revista Brasileira de Políticas Públicas, v. 9, n. 1, p. 153-172, 2019.

DÍAZ FUENZALIDA, Juan Pablo; VILLAMIL RODRÍGUEZ, Juan Sebastián. La otra cara de la moneda: protección constitucional de la empresa, el emprendimiento y la libre competencia en Chile y Colombia. Revista de Direito Internacional, Brasilia, Brasil, v. 17, n. 1, p. 230-256, 2020.

DÍAZ TOLOSA, Regina Ingrid. Aplicación judicial en Chile del "ius cogens" como manifestación de la internacionalización del Derecho interno en materia de protección de la dignidad humana. Revista de Derecho de la Pontificia Universidad Católica de Valparaíso, Valparaíso, n. 40, p. 393-417, 2013.

DÍAZ TOLOSA, Regina Ingrid. Expulsion of aliens: the application of International Law by Chilean Superior Courts. Revista de Direito Internacional, Brasilia, v. 17, n. 2, p. 308-330, 2020.

GOZAÍNI, Osvaldo. Derecho Procesal Transnacional: los procedimientos en la Comisión y ante la Corte Interamericana de Derechos Humanos. México: Tirant lo Blanch, 2014.
IRTI, Natalino. La edad de la descodificación. España: J. M. Bosch Editor, 1992.

MARTÍN-RETORTILLO BAQUER, Lorenzo. Una visión de la tutela judicial a partir de la jurisprudencia de la Corte Interamericana y del Tribunal Europeo de Derechos Humanos. In: FERRER MAC GREGOR, Eduardo; HERRERA GARCÍA, Alfonso (coord.). Diálogo jurisprudencial en derechos humanos: entre Tribunales Constitucionales y Cortes Internacionales: in memoriam Jorge Carpizo, generador incansable de diálogos. México: Tirant lo Blanch, 2013. p. 1217-1260.

MORALES, Alejandra Virginia Morales; ODIMBA ON'ETAMBALAKO WETSHOKONDA, Jean Cadet. La incorporación del concepto del bloque de constitucionalidad en matéria de derechos humanos en México. Prolegómenos: Derechos y Valores, Bogotá, v. 12, n. 27, p. 135-14, ene./jun. 2011.

NACIONES UNIDAS. Convención de Viena sobre el Derecho de los Tratados, Resolución A/CONF.39/27, de 23 de mayo de 1969. Disponible en: https://treaties.un.org/ doc/Treaties/1980/01/19800127\%2000-52\%20AM/ Ch_XXIII_01.pdf Acceso en: 26 oct. 2020.

NACIONES UNIDAS. Declaración Universal de Derechos Humanos, de 1948. Disponible en: https://www.un.org/ es/universal-declaration-human-rights/ Acceso en: 26 oct. 2020 .

NACIONES UNIDAS. Historia de la redacción de la Declaración Universal de Derechos Humanos. Disponible en: http://www.un.org/es/documents/udhr/history.shtml Acceso en: 26 oct. 2020.

NACIONES UNIDAS. Status of Treaties: Chapter XXIII. Law of Treaties. 1. Vienna Convention on the Law of Treaties. Disponible en: https://treaties.un.org/ doc/Publication/MTDSG/Volume\%20II/Chapter\%20XXIII/XXIII-1.en.pdf Acceso en: 26 oct. 2020.

NOGUEIRA ALCALÁ, Humberto. Los derechos esenciales o humanos contenidos en los tratados internacionales y su ubicación en el ordenamiento jurídico nacional: doctrina y jurisprudencia. Ius et Praxis, Talca, v. 9, n. 1, p. 403-466, 2003.

ORGANIZACIÓN DE LOS ESTADOS AMERICANOS. Convención americana para facilitar la asistencia en casos de desastre. Resolución A-54, de 16 de noviembre de 1996. Disponible en: http://www.oas.org/juridico/ spanish/tratados/a-54.html Acceso en: 26 oct. 2020. 
ORGANIZACIÓN DE LOS ESTADOS AMERICANOS. Convención americana sobre derechos humanos. Resolución B-32, de 22 de noviembre de 1969. Disponible en: http://www.oas.org/dil/esp/tratados_B-32_Convencion_Americana_sobre_Derechos_Humanos_firmas. htm Acceso en: 26 oct. 2020.

ORGANIZACIÓN DE LOS ESTADOS AMERICANOS. Convención interamericana contra el racismo, la discriminación racial y formas conexas de intolerância. Resolución A-68. Disponible en: http:// www.oas.org/es/sla/ddi/tratados_multilaterales_ interamericanos_A-68_racismo.asp Acceso en: 26 oct. 2020 .

ORGANIZACIÓN DE LOS ESTADOS AMERICANOS. Convención interamericana contra toda forma de discriminación e intolerância. Resolución A-69. Disponible en: http:/ / www.oas.org/es/sla/ddi/tratados_multilaterales_interamericanos_A-69_discriminacion_intolerancia_firmas.asp Acceso en: 26 oct. 2020.

ORGANIZACIÓN DE LOS ESTADOS AMERICANOS. Convención interamericana para prevenir y sancionar la tortura. Resolución A-51, de 9 de diciembre de 1985. Disponible en: http://www.oas.org/juridico/spanish/ tratados/a-51.html Acceso en: 26 oct. 2020.

ORGANIZACIÓN DE LOS ESTADOS AMERICANOS. Convención interamericana sobre concesión de los derechos políticos a la mujer. Resolución $A-44$, de 2 de mayo de 1948. Disponible en: http://www.oas.org/ juridico/spanish/tratados/a-44.html Acceso en: 26 oct. 2020.

ORGANIZACIÓN DE LOS ESTADOS AMERICANOS. Convención interamericana sobre concesión de los derechos civiles a la mujer. Resolución $A-45$, de 2 de mayo de 1948. Disponible en: http://www.oas.org/juridico/spanish/tratados/a-45.html Acceso en: 26 oct. 2020.

ORGANIZACIÓN DE LOS ESTADOS AMERICANOS. Convención interamericana sobre desaparición forzada de personas. Resolución A-60, de 9 de junio de 1994. Disponible en: http://www.oas.org/juridico/ spanish/tratados/a-60.html Acceso en: 26 oct. 2020.

ORGANIZACIÓN DE LOS ESTADOS AMERICANOS. Convención interamericana para prevenir, sancionar y erradicar la violencia en contra de la mujer. Resolución A-61, de 9 de junio de 1994. Disponible en: http:// www.oas.org/juridico/spanish/tratados/a-61.html Acceso en: 26 oct. 2020.

ORGANIZACIÓN DE LOS ESTADOS AMERICANOS. Convención interamericana para la eliminación de todas las formas de discriminación contra las personas con discapacidad. Resolución A-65, de 7 de junio de 1999. Disponible en: http://www.oas.org/juridico/spanish/tratados/a-65.html Acceso en: 26 oct. 2020.

ORGANIZACIÓN DE LOS ESTADOS AMERICANOS. Convención interamericana contra el terrorismo. Resolución A-66, de 3 de junio de 2002. Disponible en: http:/ /www.oas.org/juridico/spanish/tratados/a-66. html Acceso en: 26 oct. 2020.

ORGANIZACIÓN DE LOS ESTADOS AMERICANOS. Convención interamericana sobre la protección de los derechos humanos de las personas mayores. Resolución A-70, de 15 de junio de 2015. Disponible en: http://www.oas.org/es/sla/ddi/tratados_multilaterales_interamericanos_A-70_derechos_humanos_personas_mayores.asp Acceso en: 26 oct. 2020.

ORGANIZACIÓN DE LOS ESTADOS AMERICANOS. Declaración Americana de los Derechos y Deberes del Hombre, de 1948. Disponible en: http://www.oas.org/ es/cidh/mandato/Basicos/declaracion.asp Acceso en: 26 oct. 2020.

ORGANIZACIÓN DE LOS ESTADOS AMERICANOS. Protocolo a la Convención Americana sobre derechos humanos relativos a la abolición de la pena de muerte. Resolución A-53, de 8 de junio de 1990. Disponible en: http://www.oas.org/juridico/spanish/ tratados/a-53.html Acceso en: 26 oct. 2020.

ORGANIZACIÓN DE LOS ESTADOS AMERICANOS. Protocolo adicional a la Convención americana sobre derechos humanos en materia de derechos económicos, sociales y culturales. Resolución A-52, de 17 de noviembre de 1988. Disponible en: http://www.oas. org/juridico/spanish/Tratados/a-52.html Acceso en: 26 oct. 2020.

PAÚL DÍAZ, Álvaro. La Génesis de la Declaración Americana de los Derechos y Deberes del Hombre y la Relevancia Actual de sus Trabajos Preparatorios. Revista de Derecho de la Pontificia Universidad Católica de Valparaíso, Valparaíso, n. 47, p. 361-395, 2016. 
PEREIRA, Ruitemberg Nunes. Interações transjudiciais e transjudicialismo: sobre a linguagem irônica no direito internacional. Revista de Direito Internacional, Brasilia, v. 17, n. 2, p. 169-199, 2020.

TOMÉ DA MATA, Edilney; GOMEZ CORREIO, Eduardo Bianchi. Responsabilidad Internacional del Estado frente a lucha contra la discriminación racial y étnica en España. Revista de Direito Internacional, Brasilia, v. 13, n. 1, p. 347-363, 2016.

VARELLA, Marcelo. D. Internacionalização do Direito: superação do paradigma estatal e a insuficiência de estruturas de diálogos. Revista de Direito Internacional, v. 9, n. 4, p. 1-5, 2012. 
Para publicar na Revista de Direito Internacional, acesse o endereço eletrônico www.rdi.uniceub.br ou www.brazilianjournal.org.

Observe as normas de publicação, para facilitar e agilizar o trabalho de edição. 